American J. of Engineering and Applied Sciences 3 (4): 765-768, 2010

ISSN 1941-7020

(C) 2010 Science Publications

\title{
A Simplified Analytical Modeling of the Hole Erosion Test
}

\author{
${ }^{1}$ Mohammed Bezzazi, ${ }^{1}$ Abdellatif Khamlichi, ${ }^{2}$ Miguel Prron Vera, \\ ${ }^{2}$ Maria Dolores Cintas Rubio and ${ }^{2}$ Castillo Lopez Olegario \\ ${ }^{1}$ Modeling and Simulation of Mechanical Systems Laboratory, Department of Physics, \\ Faculty of Sciences at Tetouan, BP 2121, M'hannech, Tetouan 93002, Morocco \\ ${ }^{2}$ Department of Mechanical and Civil Engineering, Polytechnic High School of Algeciras, \\ Cadiz University, Ramon Pujol Avenue,Algeciras 11202, Spain
}

\begin{abstract}
Problem statement: Internal erosion occurs in soils containing fine particles under the action of high pressure gradients that could result from water discharge. This phenomenon can yield in its final stage to the formation of piping which constitutes a real threat for hydraulics infrastructures as it can precipitate their entire rupture in very short time. In order to mitigate this insidious hazard, it is important to characterize piping dynamics. In this context, the Hole Erosion Test was introduced to assess the erosive features of soils by means of two parameters, the erosion rate and the critical shear stress indicating the beginning of erosion. Modeling this test can enable to understand more comprehensibly the piping phenomenology. Approach: A simplified analytical modeling of the Hole Erosion Test was considered in this study. A closed form solution of erosion taking place during piping was derived without resorting to the habitual cumbersome developments that are needed to achieve complete solution of the rational equations describing this highly coupled problem. This was achieved by assuming formal analogy between the erosive shear stress and the friction shear that develops at a cylindrical piping wall under an axial viscous flow. The flow was assumed to be uniform along the tube. Results: A closed form analytical formula describing erosion dynamics associated to piping was derived. Theoretical predictions were compared with experimental results and the simplified model was found to predict accurately the increase of flow rate that results from piping erosion. Conclusion/Recommendations: The one-dimensional modeling that was proposed for the Hole Erosion Test under strong simplifying assumptions was found to yield the same features as those obtained in the literature by using other approaches. It gives furthermore the dynamics as function of the fluid regime existing inside the tube. In order to get further insight regarding the flowing flow action, which could be non uniform during erosion, more advanced modeling is needed.
\end{abstract}

Key words: Surface erosion, hydraulic piping, hole erosion test

\section{INTRODUCTION}

Internal erosion and hydraulic piping are the main cause of dam failure (Foster et al., 2000). In order to characterize soil resistance to erosion phenomenon, a lot of experimental testing protocols have been developed since 1962, (Fell et al., 2003) and (Wan and Fell, 2004). A recent test was introduced in 2004 by Wan and Fell (2004). It consists of an erosion experiment conducted on a perforated sample which is extracted from the soil to be analyzed. This experiment was found to yield a good characterization of soil erosion resistance parameters in case this phenomenon is to develop in cavities and hydraulic piping. It enables determining erosion rate and a stress threshold indicating the commencement of erosion phenomenon. A scale varying from 1-6 was introduced in order to quantify soil resistance under the action of a flowing flow taking place inside soil cavities. Lim (2006) has used this test to study the erosion rate as function of the saturation degree in case of clayey soils. Bonelli et al. (2006) and Lachouette et al. (2008) have presented an analytical modeling of this test. These authors obtain an approximated formula which gives the inner tube radius evolution as function of time. But, realistic assumptions about the flowing fluid regime and the friction coefficient of the flowing fluid against the inner tube wall were not clearly mentioned. In this study, a rational modeling of the hole erosion test is proposed, where different fluid flowing regimes through the tube

Corresponding Author: Mohammed Bezzazi, Modeling and Simulation of Mechanical Systems Laboratory, Department of Physics, Faculty of Sciences at Tetouan, BP 2121, M'hannech, Tetouan 93002, Morocco 
are taken into account. Among the main hypotheses that have been stated, it is assumed that only a one dimensional flow is likely to occur inside the tube and that the inner wall is perfectly impermeable such that no radial flow takes place. On the other hand, surface erosion which consists in material departure from the inner wall of the tube is assumed to be uniform along the whole tube length. The flowing fluid velocity is assumed also to be uniform across all the tube sections and equal to the mean axial flowing fluid velocity. In addition, the fluid density, the kinematics viscosity and the friction coefficient of fluid flow against the tube wall are assumed constant and not affected by the eroded particles extracted from the tube wall. Finally, the hydraulic gradient is kept uniform and constant if one maintains a constant hydraulic head resulting from constant pressures imposed at the tube inlet and outlet ends.

Under these hypotheses, the inner tube radius time evolution is obtained as the solution of a linear differential equation of first order having constant coefficients. Two phenomenological constants characterizing surface erosion mechanism taking place inside the tube are exhibited. The first one is the response characteristic time which is essentially related to the erosion rate and the imposed hydraulic gradient. The second one is a threshold parameter indicating in terms of the actual shear stress acting at the tube wall when surface erosion phenomenon is likely to occur. This last constant depends on the initial radius of the tube, the soil erosion resistance and the applied hydraulic gradient existing inside the hole.

\section{MATERIALS AND METHODS}

The Hole Erosion Test (HET) consists in introducing inside a standard mould a cylindrical sample of soil that is to be tested against surface erosion. The sample length is $\mathrm{L}=117 \mathrm{~mm}$. A hole of 6 $\mathrm{mm}$ of diameter is perforated along the longitudinal axis of the cylinder. A constant hydraulic head is applied between the tube extremities. Depending on the soil constitution, the inlet hydraulic head is fixed at a level exceeding the outlet head by $50-1200 \mathrm{~mm}$.

Figure 1 presents the experimental setup used during the HET. Figure 2 presents the forward and backward faces of the tested sample just before mounting it.

Surface erosion taking place inside the tube wall is assumed to be essentially a one dimensional phenomenon. In addition, all the physical quantities intervening in the problem are assumed to be uniform along the tube such that only the time is intervening as a dependant variable in the problem. The inner tube wall is assumed to be impermeable and no radial flow exists, so that conservation of the fluid flow is satisfied at every instant. Material departure caused by surface erosion which happens at the inner sample wall is assumed to be uniform along the whole tube length, L. The flowing fluid velocity is also assumed to be constant at every tube section. During the test constant pressures are maintained at the inlet and outlet ends such that the resulting hydraulic gradient is kept constant. Are assumed constant also, the fluid density $\rho_{w}$, the kinematics viscosity $v$ the friction coefficient of the fluid flow against the tube wall $\mathrm{f}_{\mathrm{L}}$.

Let's observe that these assumptions constitute a simplified approximation of the real problem. In particular, the implicit hypothesis stating that the eroded particles do not yield significant modifications of the flowing regime and of the flow properties such density, viscosity, the erosion coefficient and the erosion threshold.

Equations governing the problem are obtained by stating the fluid equilibrium condition, the hydraulic head loss relation, the friction coefficient expression as function of the flow regime (Reynolds number), the surface erosion law, the erosion rate definition and the flowing flow expression in terms of fluid velocity.

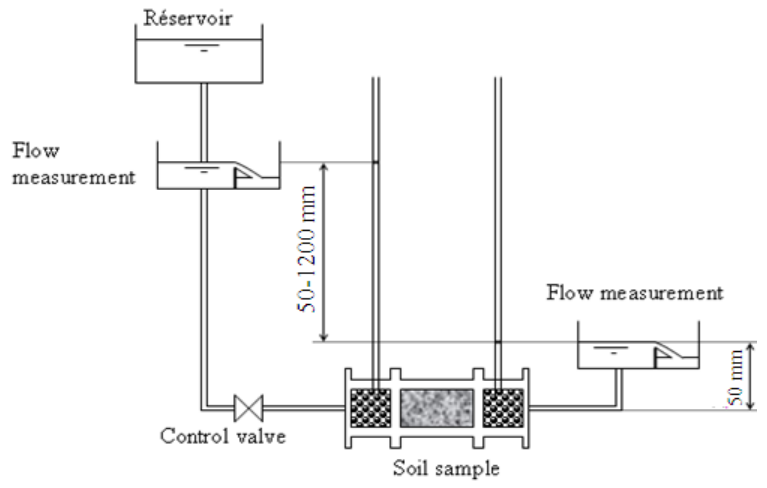

Fig. 1: Scheme of the experimental setup used to perform the hole erosion test

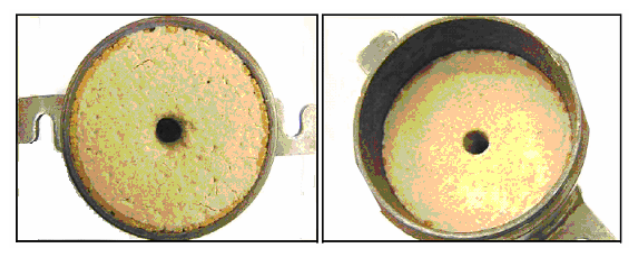

Fig. 2: Front and rear faces of the soil sample before testing 
Equilibrium condition applied to a control fluid volume delimited by the tube wall, inlet and outlet sections and the head loss expressed as function of the friction coefficient yield:

$$
\tau=\frac{\rho_{\mathrm{w}} \mathrm{v}^{2}}{8} \mathrm{f}_{\mathrm{L}}
$$

Where:

$\tau=$ The shear stress acting at the tube wall and $\mathrm{v}=$ The mean axial velocity of fluid inside the tube

The friction coefficient is obtained experimentally as function of the Reynolds number Re as:

$$
\begin{cases}\mathrm{f}_{\mathrm{L}}=\frac{64}{\operatorname{Re}}=\frac{32 v}{v R} & \text { laminar flow } \\ \mathrm{f}_{\mathrm{L}}=\frac{0.316}{\mathrm{Re}^{1 / 4}}=0.266\left(\frac{v}{v R}\right)^{1 / 4} & \text { turbulent flow }\end{cases}
$$

By recalling that the fluid flow through the tube writes $\mathrm{Q}=\pi \mathrm{R}^{2} \mathrm{v}$ and that the head loss is given by $\Delta \mathrm{P}=\frac{\rho_{\mathrm{w}} \mathrm{v}^{2} \mathrm{~L}}{4 \mathrm{R}} \mathrm{f}_{\mathrm{L}}$, Eq. 2 yields:

$$
\begin{cases}\Delta \mathrm{P}=\frac{8 \rho_{\mathrm{w}} v \mathrm{LQ}}{\pi \mathrm{R}^{4}} & \text { laminar flow } \\ \Delta \mathrm{P}=\frac{0.158}{2^{5 / 4} \pi^{7 / 4}} \frac{\rho_{\mathrm{w}} v^{1 / 4} \mathrm{~L}}{\mathrm{R}^{19 / 4}} \mathrm{Q}^{7 / 4} & \text { turbulent flow }\end{cases}
$$

Knowing that during the erosion experiment, the head loss $\Delta \mathrm{P}$ is maintained constant, one gets from Eq. 3 the actual fluid flow as function of the inner radius under the form:

$$
\begin{cases}\frac{\mathrm{Q}}{\mathrm{Q}_{0}}=\left(\frac{\mathrm{R}}{\mathrm{R}_{0}}\right)^{4} & \text { laminar flow } \\ \frac{\mathrm{Q}}{\mathrm{Q}_{0}}=\left(\frac{\mathrm{R}}{\mathrm{R}_{0}}\right)^{19 / 7} & \text { turbulent flow }\end{cases}
$$

Where:

$\mathrm{R}_{0}=$ The initial inner radius and $\mathrm{Q}_{0}=$ The initial fluid flow

The surface erosion law is stated classically (Wan and Fell, 2004), as:

$$
\dot{\varepsilon}_{\mathrm{er}}=\mathrm{c}_{\mathrm{er}}\left\langle\tau-\tau_{\mathrm{s}}\right\rangle
$$

Where:

$\dot{\varepsilon}_{\text {er }}=$ The erosion rate (in $\mathrm{kg} \cdot \mathrm{sec}^{-1} \cdot \mathrm{m}^{-2}$ ) which corresponds to the mass loss per unit time and per unit surface area

$\mathrm{c}_{\mathrm{er}}=$ The surface erosion coefficient

$\mathrm{t}_{\mathrm{s}}=$ The shear erosion limit for which erosion begins to take place

\langle\rangle$=$ The positive part of the expression

By using mass conservation of soil, one could easily arrive at:

$\dot{\varepsilon}_{\mathrm{er}}=\rho_{\mathrm{d}} \frac{\mathrm{dR}}{\mathrm{dt}}$

where, $\rho_{\mathrm{d}}$ is the dry density of soil sample.

Using Eq. 1, 5 and 6, one obtains the following linear differential equation of first order in terms of the inner radius $\mathrm{R}$ :

$$
\frac{\mathrm{dR}}{\mathrm{dt}}-\left(\frac{\mathrm{c}_{\mathrm{er}} \Delta \mathrm{P}}{2 \rho_{\mathrm{d}} \mathrm{L}}\right) \mathrm{R}=-\frac{\mathrm{c}_{\mathrm{er}} \tau_{\mathrm{s}}}{\rho_{\mathrm{d}}}
$$

Solution of this equation which is associated to the initial condition $\mathrm{R}(0)=\mathrm{R}_{0}$ writes:

$$
R(t)=\left(R_{0}-\frac{2 L \tau_{s}}{\Delta P}\right) \exp \left(\frac{c_{e r} \Delta P}{2 \rho_{d} L} t\right)+\frac{2 L \tau_{s}}{\Delta P}
$$

Expression of $\mathrm{R}$ as obtained from Eq. 8 holds only if the following condition is satisfied $\Delta \mathrm{P} \geq \frac{2 \mathrm{~L} \tau_{\mathrm{s}}}{\mathrm{R}_{0}}$. In this way, the quantity $\frac{2 L \tau_{s}}{R_{0}}$ appears to be a critical pressure that the pressure gradient must exceed in order that surface erosion takes place. This limits pressure decreases with the initial radius of the tube and increases with fluid density, tube length and soil erosion resistance.

The characteristic time of Eq. 8 is $t_{c}=\frac{2 \rho_{d} L}{c_{e r} \Delta P}$. It shows that surface erosion increases when tube length or soil dry densities are decreased or if soil erosion resistance or hydraulic gradient are increased.

Equation 7 coincides exactly with Eq. 10 given in (Bonelli et al., 2006). But, the way of its derivation is different in the actual work. Bonelli et al. (2006) have used less restrictive hypotheses at the beginning and have reinforced these hypotheses in an ambivalent manner just before giving the final version of Eq. 10 . The main difference with the previous work is that the 
flowing regime is here explicitly integrated as function of the Reynolds number. Bonelli et al. (2006) have worked with a turbulent flow and arrive at a velocity dependency given as function of the inner radius by a power law having as exponent $1 / 2$. This is in contrast with the exponent $5 / 7$ obtained in the actual work. It is stated also in our case that this exponent is given by 2 for the laminar regime flow.

\section{RESULTS}

In order to give validation of the erosion model use is made of some experimental results obtained by Wan and Fell (2004). More precisely tests referenced as: BDHET001 and JDHET001 have been selected for this purpose. Table 1 gives the experimental data related to these tests.

One should notice that the flowing regime related to these two tests is fully turbulent. Simulation performed by using Eq. 4 and 8 gives the curves depicted on Fig. 3. Experimental points are also given on this Fig. 3 .

Table 1: Experimental data for the selected tests performed by (Wan and Fell, 2004)

\begin{tabular}{llr}
\hline & Test & \\
& BDHET001 & JDHET001 \\
& (Bradys) high & $\begin{array}{c}\text { (Jindabyne) } \\
\text { clayey sand }\end{array}$ \\
Type of soil & plasticity sandy clay & 6769.00 \\
\hline $\operatorname{Re}$ & 6610.00 & 2680.00 \\
$\rho_{\mathrm{d}}\left(\mathrm{kg} \mathrm{m}^{-2}\right)$ & 2740.00 & 2.26 \\
$\mathrm{v}_{0}\left(\mathrm{~m} \mathrm{sec}^{-1}\right)$ & 2.20 & 5.89 \\
$\mathrm{c}_{\mathrm{er}}\left(10^{-4} \mathrm{sec} \mathrm{m}^{-1}\right)$ & 3.02 & 133.00 \\
$\mathrm{t}_{\mathrm{er}}\left(\mathrm{sec}^{5}\right.$ & 223.00 & 6.39 \\
$\mathrm{Q}_{\mathrm{fl}}\left(10^{5} \mathrm{~m}^{3} \mathrm{sec}^{-1}\right)$ & 6.22 & 6064.00 \\
$\Delta \mathrm{P}(\mathrm{Pa})$ & 6237.00 & \\
\hline
\end{tabular}

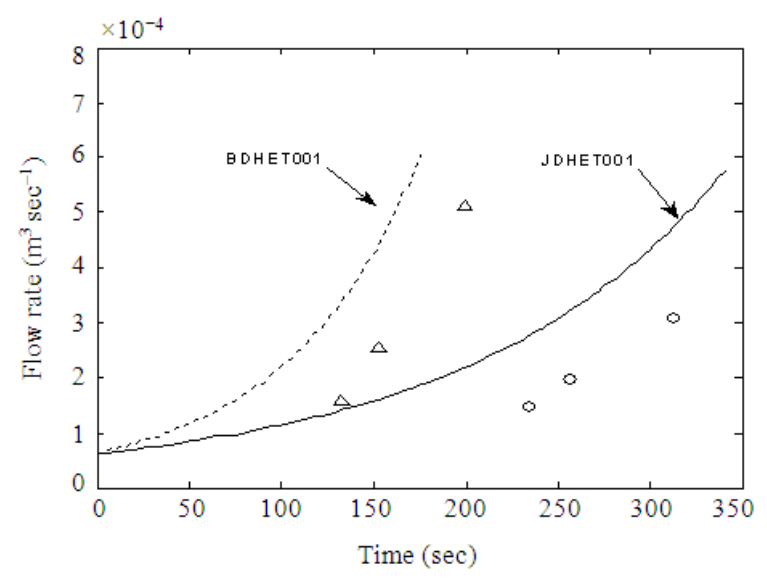

- - Simulation BDHET001 - Simulation JDHET001 $\Delta$ Experiment BDHET001 O Experiment JDHET001

Fig. 3: Simulation results against experimental data

\section{DISCUSSION}

As it could be seen from Fig. 3, a good accord is obtained between simulation results and experimental data if one considers all the identification errors that affect the parameters values. The identified values of erosion shear limit are $\tau_{\mathrm{s}}=2.085 \mathrm{~Pa}$ for BDHET001 test and $\tau_{\mathrm{s}}=1.938 \mathrm{~Pa}$ for JDHET001 test.

\section{CONCLUSION}

A simplified analytical model has been derived in order to represent the standard Hole Erosion Test for all flowing fluid regimes. The obtained model enables to catch the main phenomenological features describing the surface erosion occurring inside the tube. The model enables to find the same equation governing the inner radius time variations as given in literature but predicts different evolution of the fluid flow. Comparison with available experimental data has shown good accord.

\section{REFERENCES}

Bonelli, S., O. Brivois, R. Borghi and N. Benahmed, 2006. On the modeling of piping erosion. CR Mécanique, 22: 225-244. DOI: 10.1016/j.crme.2008.06.007

Fell, R., C.F. Wan, J. Cyganiewicz and M. Foster, 2003. Time for development of internal erosion and piping in embankment dams. J. Geotech. Geoenviron. Eng., 129: 307-314. DOI: 10.1061/(ASCE)1090-0241(2003)129:4(307)

Foster, M.A., R. Fell and M. Spannangle, 2000. The statistics of embankment dam failures and accidents. Can. Geotech. J., 37: 100-1024. DOI: 10.1139/cgj-37-5-1000

Lachouette, D., F. Golay and S. Bonelli, 2008. Onedimensional modeling of piping flow erosion. Comput. Rendus Mécanique, 336: 731-736. DOI: 10.1016/j.crme.2008.06.007

Lim, S.S., 2006. Experimental investigation of erosion in variably saturated clay soils. Ph.D. Thesis, The University of New South Wales. http://handle.unsw.edu.au/1959.4/26159

Wan, C.F. and R. Fell, 2004. Investigation of rate of erosion of soils in embankment dams. J. Geotech. Geoenviron. Eng., ASCE, 130: 373-380. DOI: 10.1061/(ASCE)1090-0241(2004)130:4(373) 